Journal of Community \& Applied Social Psychology

J. Community Appl. Soc. Psychol., 22: 453-469 (2012)

Published online 3 October 2011 in Wiley Online Library

(wileyonlinelibrary.com) DOI: 10.1002/casp.1125

\title{
Using Social Representations Theory to Examine Lay Explanation of Contemporary Social Crises: The Case of Ireland's Recession
}

\author{
CLIODHNA O'CONNOR* \\ University College London, Division of Psychology and Language Sciences, 26 Bedford Way, London WC1H \\ OAP, United Kingdom
}

\begin{abstract}
Social actors operate under a basic imperative to construct explanations for the events that surround them. Many issues that dominate the societal agenda today are not available to direct perception, derive from traditionally expert domains and are relatively remote from immediate local experience. This presents a challenge for lay explanation of these issues. Social representations theory offers a useful framework through which the construction of lay explanation for such issues can be examined. The current study recruited this theoretical framework to investigate lay explanations of the recent economic recession in Ireland. Data consisted of semi-structured interviews with 14 members of the public and a web-based survey $(N=138)$. The data suggested that explanations for the recession could be organised into three major themes: Power, Ordinary People and Fatalism. Strictly economic explanations were eschewed; instead, people drew upon a wide range of ideas about society, politics, morality, public spheres and personhood. The implications of these findings for understanding lay explanation of contemporary social crises are discussed. Copyright (c) 2011 John Wiley \& Sons, Ltd.
\end{abstract}

Key words: blame; economic thought; fatalism; Ireland; lay explanation; power; recession; risk society; social representations

\section{INTRODUCTION}

The global financial crisis that began in 2008 shook many societies to their core, none more so than the Republic of Ireland where effects of the crisis were felt particularly acutely. Between 1990 and 2007 — often characterised as the 'Celtic Tiger' era — Irish economic output had quadrupled (Kelly, 2010). However, in autumn 2008, the combination of an international liquidity crisis and the collapse of Irish property prices led the effective failure of Ireland's domestic banking sector, necessitating substantial government

*Correspondence to: Cliodhna O'Connor, University College London, Division of Psychology and Language Sciences, 26 Bedford Way, London WC1H 0AP, United Kingdom.

E-mail: cliodhna.oconnor.10@ucl.ac.uk 
bailouts. From 2008 to 2010, GNP contracted by $18 \%$ and unemployment rose from $5 \%$ to $14 \%$ (CSOI, 2010). In Ireland, the sharp descent into recession was met with bewilderment on the part of the political and economic elite and the general public alike. It was clear that the effects of the crisis were things for which the country was structurally, socially and psychologically unprepared.

\section{Lay explanation of contemporary social crises}

In a context of confusion engendered by such a crisis, people are motivated to construct understandings that establish solid points of reference through which they can conceptually adjust to the situation. Research indicates that search for explanation accounting for why the event happened - is stimulated by negative and unexpected events (Försterling, 2001). Explaining social events is one of the central mechanisms through which we orient ourselves to the world; Hume (1740/2007) described causal inference as 'the cement of the universe' (p. 417). Gustav Ichheiser, one of the first scholars to study causal explanation systematically, was drawn to the topic by its social importance, writing that the role of societies' attributional processes in the lead-up to World War II was 'hardly possible to exaggerate' (Ichheiser, 1949, p.47). People are called - implicitly as social actors and explicitly as citizens - to explain the problems faced by society (Hewstone, 1989). The explanations produced have weighty implications, determining who is afforded responsibility to deal with problems and what measures are deemed appropriate to do so. Uncovering the lay epistemology of societal problems is therefore a critical task in understanding our social world.

For most laypeople, the process of explaining a crisis like economic recession is not straightforward. Sociologists have characterised our age as one of constant impending catastrophe, in which the threat of social, technological or environmental collapse is never far from the agenda. This is theoretically embodied in the risk society thesis developed by the sociologist Ulrich Beck (1992). While the resources of post-industrial society have administered control over many of the hazards that blighted previous times, technological advances have simultaneously spawned a new set of risks - like environmental pollution, nuclear accidents and food contamination - that threaten our social order and material existence and dominate the political landscape of Western societies. The problems typical of the risk society are defined by a number of distinctive features to which the recent recession can be seen to conform. First, it was a global event that largely transcended national boundaries. Second, economic processes are invisible and not available to direct perception. Third, understanding its origin and development requires specialised knowledge: people cannot see or directly experience phenomena like economic recession and rely on experts to identify and characterise them. Fourth, it resulted from human activities, but it is difficult to pinpoint distinct groups or individuals to whom the problem can be unambiguously attributed.

It is likely that these four features make the recession resistant to simple causal explanation. Their effect is to remove the crisis from people's everyday realities; it is not a matter of local, immediate experience and must be conceptualised at an abstract rather than a directly experiential level. When an issue is not available to direct experience or perception, the construction of its explanation must be a socially constituted process. Research supports the pivotal role of the social in economic cognition: studies have identified socialisation (rather than direct experience) as critical in the development of children's economic 
concepts (Bonn, Earle, Lea \& Webley, 1999; Sévon \& Weckström, 1989), and there are large degrees of commonality in the economic concepts held by different individuals (Leiser \& Drori, 2005). As an individual cannot look into the world and directly perceive a macro-economic process, the only way in which to 'know' the issue is through the mediation of other people or institutions, including experts, media outlets and conversational partners. Understanding how lay explanation of economic crisis develops therefore requires a theoretical framework in which the constitutive role of social context and communication processes is central.

\section{Social representations theory}

Such a framework is provided by social representations theory (SRT), a social psychological theory designed to capture the shared, common-sense and everyday representations through which people orient themselves to the world (Moscovici, 1988). SRT rejects the individualistic approach to human thought that dominates much mainstream psychology and shifts concern from knowledge as an individual property to knowledge grounded in the intersubjective world of a community (Jovchelovitch, 2007). This makes it appropriate for examining economic issues, independent explanation of which is not an option available to most people. SRT provides a lens through which one can track how social resources are drawn upon in order to satisfy the imperative to explain events. Applications of SRT to responses to public issues have proved fruitful in domains such as health (e.g. Jodelet, 1991; Joffe \& Haarhoff, 2002) and science and technology (e.g. Bauer, 2009; Wagner \& Kronberger, 2001).

The social representational process is driven by people's motivation to 'know' the world around them by 'making the unfamiliar familiar' (Moscovici, 1961/2008). This development of understanding is achieved through two processes. First, the new phenomenon is anchored in phenomena with which the community is already familiar, and the meanings attached to the familiar phenomena influence how the new phenomenon is represented (Moscovici, 1988). The second process is objectification, in which the initially abstract new idea is concretized by grounding the representation in a tangible object, image or concept. Bauer and Gaskell (1999) give the example of genetic engineering in the 1990s being anchored in the idea of 'cloning' and objectified in the figure of 'Dolly the sheep'. The relevance of these processes for examining lay explanations of risk society crises like the recession is that they provide a means by which the crises' distinctly abstract nature can be brought into the domain of immediate apprehension. Recruitment of these theoretical concepts is therefore likely to offer significant advantage in understanding how the recession has been comprehended by the public.

SRT is especially concerned with how knowledge that is produced in the 'reified universe' of science and expertise diffuses through society to the 'consensual universe' populated by the general public, becoming transformed in the process. Thus, it acknowledges the influence of expert evaluations in public representation, but does not assume that these are simply transplanted intact into the minds of the populace. Expert pronouncements are reframed, reconstituted and sometimes actively resisted (Jovchelovitch, 2008), and this process is driven by meaningful social interests rather than individual cognitive biases. Joffe, Washer and Solberg's (2011) study examining public perceptions of the hospital infection methicillin-resistant Staphylococcus aureus (MRSA) found that the accepted medical explanation for MRSA — antibiotic overuse — tended to be overlooked in favour 
of explanations anchored in ideas of dirty hospitals, foreign hospital staff and structural problems with the National Health Service. Thus, people do not approach a new issue with a mental blank slate but through the lens of existing sets of worldviews and representations, resulting in explanations that incorporate a broader range of concerns than typically found in decontextualised expert evaluations. An SRT approach allows these concerns to emerge, thereby facilitating not just a picture of representations of the issue under direct scrutiny, but establishing an insight into the wider concerns that structure people's experience of specific social contexts.

As a framework, SRT represents a move away from the rationalistic tradition that dominates much of psychology. Social representations are not 'cold' knowledge structures but are underpinned by social and emotional motivations (Joffe, 2003). A central motivational foundation of the social representational process is identity protection (Howarth, 2002). The identity functions of social representations become particularly apparent when a community is confronted with a threatening phenomenon. Research indicates that in such a case, the risk is often projected onto an 'other' or outgroup, thereby protecting the self from blame or symbolic contamination. Joffe (1999) documents how at the height of the HIV/AIDS epidemic, symbolisation of the disease as a 'gay plague' served to distance the majority from the threat itself and from its associated social censure. SRT thus provides a useful lens for exploring how the identity dynamics of a society feed into public reactions to an impinging threat.

There seems to be a certain fit between these dimensions of social representation and the characteristics of risk society-type problems outlined earlier. Typical risk society issues cannot be accessed through direct experience: explanations must be constructed socially, the process of which is captured by SRT. The issues are invisible: they can be made tangible through anchoring and objectification processes. Further, they require specialised knowledge: SRT explicitly designates a role for experts and authorities, but treats their pronouncements as funnelled into a wider network of lay knowledge that is meaningful on its own terms. Additionally, responsibility for their causation is ambiguous: the identity dynamics of social representation may aid in resolution of this ambiguity. Social representation thus offers several means by which people can resolve the abstract nature of risk society-type issues, representing them in such a way as to make them accessible to direct apprehension.

\section{Social representations of the financial crisis}

SRT therefore appears to be an appropriate framework in which to locate explorations of public reactions to the recent financial crisis. This was recognised in studies by Leiser, Bourgeois-Gironde and Benita (2010) and Roland-Lévy, Pappalardo Boumelki and Guillet (2010), both of which applied SRT to analyses of public perceptions of the crisis. The Leiser et al. (2010) study comprised a questionnaire completed by 1707 people in France, the US, Russia, Germany, Israel and sub-Saharan Africa. Factor analysis revealed two major conceptions of the crisis, one (the most pervasive) focusing on the role of morally or cognitively flawed individuals, and another relying on understandings of the economy as a system largely independent from human intentions. Roland-Lévy et al. (2010) also administered a questionnaire, asking 275 French participants to provide words or expressions that they associated with the word 'crisis'. People spontaneously associated the crisis with ideas like economy, unemployment, difficulties and finances. The Leiser et al. (2010) 
and Roland-Lévy et al. (2010) studies both contribute valuable data on public understandings of the economic crisis. However, the reliance of both on questionnaire data means that there is a limit to the depth of analysis possible. Participants were restricted to predefined response types, and a comprehensive depiction of the anchoring, objectification and identity dynamics of the social representations is difficult to formulate from this data.

The current study attempted to deepen analysis of social representations of the crisis by recruiting qualitative interview methodology to explore lay explanations for Ireland's economic recession. Interviews allow people to contextualise and elaborate on their responses, thereby facilitating not just the identification of the particular ideas circulating in a society but also observation of their meaning and function in particular social and emotional contexts. The study drew on interviews with 14 people. A survey of 138 people was also conducted to provide confidence that the themes identified in the interviews were present among a wider population segment. The aim was to identify patterns present in Irish people's explanations of the recession in spring-summer 2010, a time when the issue was paramount in the public agenda.

\section{INTERVIEWS}

\section{Method}

Informants. Ten semi-structured individual interviews with Irish citizens were conducted in locations across Ireland in April 2010. Potential informants were identified through online advertisements and snowballing. Selection of informants was guided by the aim of accessing a range of different population segmentations, so as to secure a variety of perspectives and experiences (Gaskell, 2000). Table 1 lists the informants.

A group interview was also conducted to observe how the recession was discussed in a more naturalistic social context (Gaskell, 2000). The interview transcripts were inspected to identify an appropriate population from which to recruit participants. Several informants mentioned recent university graduates in speaking about the recession's consequences, but to different purposes: some identified them as among the worst affected groups, while others represented them as immune from the recession. It was thought that this variation in representations of graduates might make them an interesting population of study. Four people who had graduated in the previous two years (pseudonyms Aileen, Declan, Eoin and Orla) agreed to take part.

Table 1. Individual interview informants

\begin{tabular}{llcl}
\hline Pseudonym & Sex & Age & \multicolumn{1}{c}{ Occupation } \\
\hline Anne & Female & 27 & Teacher \\
Barbara & Female & 49 & Sales Assistant \\
Caroline & Female & 48 & Disability Advocate \\
Frank & Male & 56 & Construction Director \\
Kate & Female & 27 & Student \\
Liam & Male & 40 & Line Technician \\
Paul & Male & 50 & School Principal \\
Robert & Male & 74 & Agricultural Advisor (Retired) \\
Sean & Male & 39 & Civil Servant \\
Tom & Male & 45 & Programme Analyst \\
\hline
\end{tabular}


Procedure. All interviews took place in locations convenient for informants, usually in their homes. Interviews were semi-structured. A topic-guide of questions probing informants' explanations for the recession was developed to guide the interviews. The interviews began by asking informants what they would position as the starting point of the recession, and then asked them to recount its progress to the present date. Other questions addressed perceptions of the causation of the crisis and its impact on the informants personally and on society in general. The topic guide was used flexibly rather than prescriptively, in order to allow informants to direct attention to areas not pre-empted by the interviewer. Interviews lasted between 30 and 60 minutes.

Analysis. The interview transcriptions were subjected to thematic analysis using ATLAS.ti 6. Thematic analysis can be defined as 'a method for identifying, analysing and reporting patterns (themes) within data' (Braun \& Clarke, 2006, p. 79). Initially, the transcripts were read through several times, with any emerging ideas or questions noted using the memo facility of ATLAS.ti. These notes were gradually developed into a coding frame for the analysis. Codes were essentially descriptive labels that captured the immediate content of data segments. This coding frame was applied systematically to the data by the researcher, with data segments 'tagged' with relevant codes. The content of each code (i.e. the quotes and memos corresponding to it) was then examined with a view to broadening the analytic focus to the level of themes. Relationships between the codes were considered, and codes addressing similar issues were grouped together to produce a set of themes. These were reviewed and refined to ensure that they were supported by sufficient data, clearly defined, internally coherent and distinct from each other.

\section{Results}

The thematic analysis of the interview data identified three major themes underlying explanations of the recession: Power, Ordinary People and Fatalism.

\section{Power}

Power inequalities. Understandings of the recession were heavily anchored in ideas about how power operates. The data revealed a perception that power in Ireland is distributed unequally, and that this contributed to the economic crash. Power was represented as concentrated within select groupings, at the expense of a chronically disempowered general public. People questioned the democratic nature of Irish public life, seeing little opportunity for the general public to participate or for their interests to be represented.

The constitution and the laws governing us are in the hands of very few people (...) People (...) don't see themselves as having a big input into democracy or government or anything like that. (Robert)

Banker-Politician-Developer 'triad'. The powerful were objectified using the concept of a 'triad' of the banking, political and property development fields. This idea of a 'triad', 'triumvirate' or 'triangle' was repeatedly introduced and seemed to form the symbolic core of representations of the recession.

Between the politicians, the banks and the developers - that triumvirate or whatever you call it, the triangle of the three of them - the power that sat with them. (Sean) 
The 'triad' was represented as internally united and distinctly separate from the rest of the population. The three bodies were seen to be in a mutually beneficial relationship, acting in each other's favour while disregarding the interests of the rest of the population. They were positioned as responsible for the recession, and informants expressed resentment that they were not taking a proportional share of its consequences.

There doesn't seem to be payback for them like there's payback for everyone else. (Paul)

Banks were particularly salient as the primary causal agent. The term 'bankers' seems to have been invested with major symbolic meaning following the recession. When the terms 'bankers' or 'the banks' were used, they seemed to be intended to communicate more than their literal meaning and were laden with emotional connotations of contempt, anger and blame.

Again it comes back to the banks again for me, I don't know why but it just does (. . .) I suppose I see them as greedy and the ones behind it all. (Anne)

There was an element of 'othering' in the way the 'triad' was represented. A clear usthem dynamic pervaded the manner in which people spoke about it. Representing these sectors as 'other' and attributing blame to them could serve defensive purposes, removing culpability from the self and 'ordinary people like me'. It also points to a serious distrust that those in power will behave responsibly or fairly.

It's one rule for the wealthy in this country and there's another rule altogether for the people in the middle to lower class. (Barbara)

Traits of the powerful agents. Interrogation of the representations of the 'triad' revealed a number of traits attached to its participants. Informants repeatedly framed the actions of the 'triad' in moral terms, judging their behaviour as morally corrupt. They were seen as fundamentally motivated by self-interest and greed. In pursuit of their interests, they were portrayed as intentionally deceiving the public.

If they'd had a bit more moral respect for their job and not just gone on these, you know, profitgaining things. (Kate)

There was also an element of doubt as to the competence of the powerful to fulfil their duties. They were represented as acting foolishly and without foresight, and several informants spoke disparagingly of their intellectual abilities.

They don't have the expertise and the intelligence. (Caroline)

\section{Ordinary People}

Ordinary people's responsibility. While those in power were the principal symbolic focus of people's explanations, there was also some reluctance to project all blame onto other parties. There was a recurring sentiment that everybody must now contribute to Ireland's recovery efforts. This 'collective hit' was sometimes portrayed as justified simply by pragmatic necessity.

You're going to have to claw money back from the multitude because that's where the money is. That's the only place where money is, because there's no money left in the banks. (Sean) 
Other times, however, it was portrayed as morally necessary: ordinary people morally should make personal sacrifices to resolve the economic situation. Representations of ordinary people as morally responsible for suffering the recession's consequences derive from perceptions that they were involved in the processes that produced it: the activity patterns perceived to have driven the recession (e.g. lending and borrowing practices) were ones in which most of society participated. The general public was also faulted for failing to object to questionable actions by the powerful.

We overspent in the Celtic Tiger, we spent too much money on our houses, on our cars, we went on excessive holidays. (Aileen)

I suppose we're all to blame, in the sense that we didn't stand up and march. (Robert)

Ordinary people's innocence. The above statements of ordinary people's responsibility were often accompanied by qualifications removing them from direct culpability. While it was acknowledged that activity distributed throughout the population fuelled the crisis, people were quick to note that this activity did not result from intentional decisions on their part, thus mitigating their culpability. It was common for informants to state that ordinary people had no control over the processes that led to the recession. Their activity patterns were seen as determined by greater forces. In some cases, ordinary people were portrayed as manipulated by more powerful agents to behave in ways that suited their interests.

The banks were fuelling the need for property, for people to have properties, bigger and better properties and multiple properties. (Paul)

They didn't really have a choice whether to cause it or not, and now all of a sudden they have to make up for it, something they probably didn't decide to do in the first place. (Anne)

In other cases, people were represented as subject to a type of mass hallucination or herd mentality, rather than acting according to consciously thought-out decisions. People acted thoughtlessly and without reflection on potential consequences - they 'jumped on the bandwagon', 'rolled with it', 'got sucked into the craze'. Representations of people's actions in these terms acknowledge that their behaviour played a part in causing the recession, but diminish their personal accountability for its consequences.

Ordinary people's helplessness. A recurring thread through the data pointed to a feeling of helplessness amongst the general population. Informants expressed a lack of confidence that action by ordinary people could have any significant effect on the state of the country.

People are helpless, they just kind of give up trying to change things and it's almost feeling downtrodden. (Caroline)

This low efficacy in public sphere participation was often attributed to a lack of structures through which effectual action was possible. It was not that people did not want to act, but that they did not perceive anything in their environment offering a viable opportunity for action.

We didn't stand up and march... but other than that what can an ordinary person do? We have been disempowered by the system. (Robert) 


\section{Fatalism}

Essentialist representations of humans and social groups. Also present in the data was a sense that the recession was somewhat inevitable and unpreventable. Representations of intrapersonal life in deterministic ways contributed to this conviction. In discussing how the actions of ordinary people and the powerful built the situation from which the recession emerged, people often recruited ideas of 'human nature'. For example, when asked to elaborate on the origins of the greed positioned as motivating people's actions, several represented it as a natural, inevitable aspect of the human condition.

I think it's innate in human nature. (Robert)

Representations of the essential 'nature' of the banking, political and business fields were also recruited to understand the activities positioned as causing the recession. These fields were seen as socialising their participants into dispositions of greed, selfishness and deception. Such dispositions were represented as necessary ingredients for these fields to function successfully.

That's part of a good businessperson's make-up. Never telling others the full story (...) And if you take that right up the line, especially up towards people who are running banks, they have obviously those traits in abundance. That's how they've got on, that's how to get on in business. (Paul)

A further contributor towards the sense of fatalism derived from representations of the 'Irish mentality'. The national character was represented as passive and accepting of disempowerment, and this representation was used to explain the lack of objection to the practices at the root of the crash.

I think a lot of it was in the Irish psyche, to be perfectly honest. (Tom)

Uncontrollable structural forces. Further reinforcing fatalistic views were certain representations of wider structural factors over which individuals have no control. Many informants mentioned the global nature of the recession. It was sometimes implied that events within Ireland were irrelevant - no matter what happened internally, the outcome would have been the same due to Ireland's vulnerability to international economic currents.

I think what happened was outside Ireland's control. It was the fact that the world economy went into recession that it hit us. It's like if America sneezes, Ireland catches a cold. (Liam)

Also contributing to the sense of uncontrollability were representations of economic phenomena as self-directed, autonomous forces that function independently of human intentionality. Explanations of the recession in terms of 'cycles' or 'spirals' were common, for example. Economic processes were represented as almost having an intentionality of their own, divorced from any human agency.

Suddenly you had all this extra money flying around the place (...) there was lots of money flying around the place and looking for homes. (Sean) 


\section{SURVEY}

The interviews accessed a limited number and range of people. The qualitative data was therefore supplemented with a survey to establish whether the patterns identified in the interview data were present in a wider segment of the population.

\section{Method}

Respondents. Survey respondents were recruited through advertisements placed on several popular Irish websites and discussion boards in May-July 2010. The adverts contained a web URL that linked directly to the survey. Efforts were made to post the advert on a wide variety of websites. 138 people completed the survey. Of these, 50 $(40 \%)$ were male, $74(60 \%)$ female and 14 did not specify their gender. Of those who provided their age, $37 \%$ fell into the 16-25 age bracket, $42 \%$ into $26-35,15 \%$ into $36-45,5 \%$ into 46-55 and 2\% into 56-65. Using the National Statistics Socio-Economic Classification system (Office for National Statistics, 2005), 9\% were categorised as Managerial/ Professional, $34 \%$ as Intermediate and $13 \%$ as Routine/Manual, while $9 \%$ were unemployed and $34 \%$ were students.

Procedure. The survey was presented online using the website www.surveygizmo. com. The survey consisted of short descriptions of 20 possible causes of the recession (see Table 2). On a 10-point Likert scale, respondents rated the importance of each in leading to the recession. The possible causes were based on statements made by informants during the interviews; some were paraphrased to make for 'neater' survey items, but their central meaning and language were retained. Finding the survey items within the qualitative data ensured their validity, as the possible explanations were provided by community members rather than created 'from scratch' by a researcher. Each item was presented on its own page, such that each page contained a potential explanation for the recession (e.g. 'Greed of individual bankers') and a Likert scale with clearly labelled buttons from 0 to 10. To avoid any order effects, the survey programme randomised the sequence in which the 20 items were presented.

\section{Results}

Factor analysis. The 20 Likert items were subjected to Principal Components Analysis using SPSS. The scree plot indicated a break after the fourth component, suggesting that a four-factor solution was appropriate. This four-factor solution explained $54.74 \%$ of the total variance. To aid in its interpretation, Varimax rotation was performed. The rotated solution showed simple structure, with all factors displaying several strong loadings and all items loading substantially on one factor. According to convention, .3 was taken as the threshold for an item to contribute to a factor. All item communalities exceeded .3, with most over .5.

Factors 1, 2, 3 and 4 contributed $20.98 \%, 16.09 \%, 9.67 \%$ and $8 \%$ of the variance, respectively. Table 1 displays the item loadings for the four factors. All items loading primarily on Factor 1 implicate aspects of politics, banking and societal power in the recession's causation. Factor 2 refers more to the general public and the features of ordinary thought and behaviour perceived to have been involved in the processes leading to the 


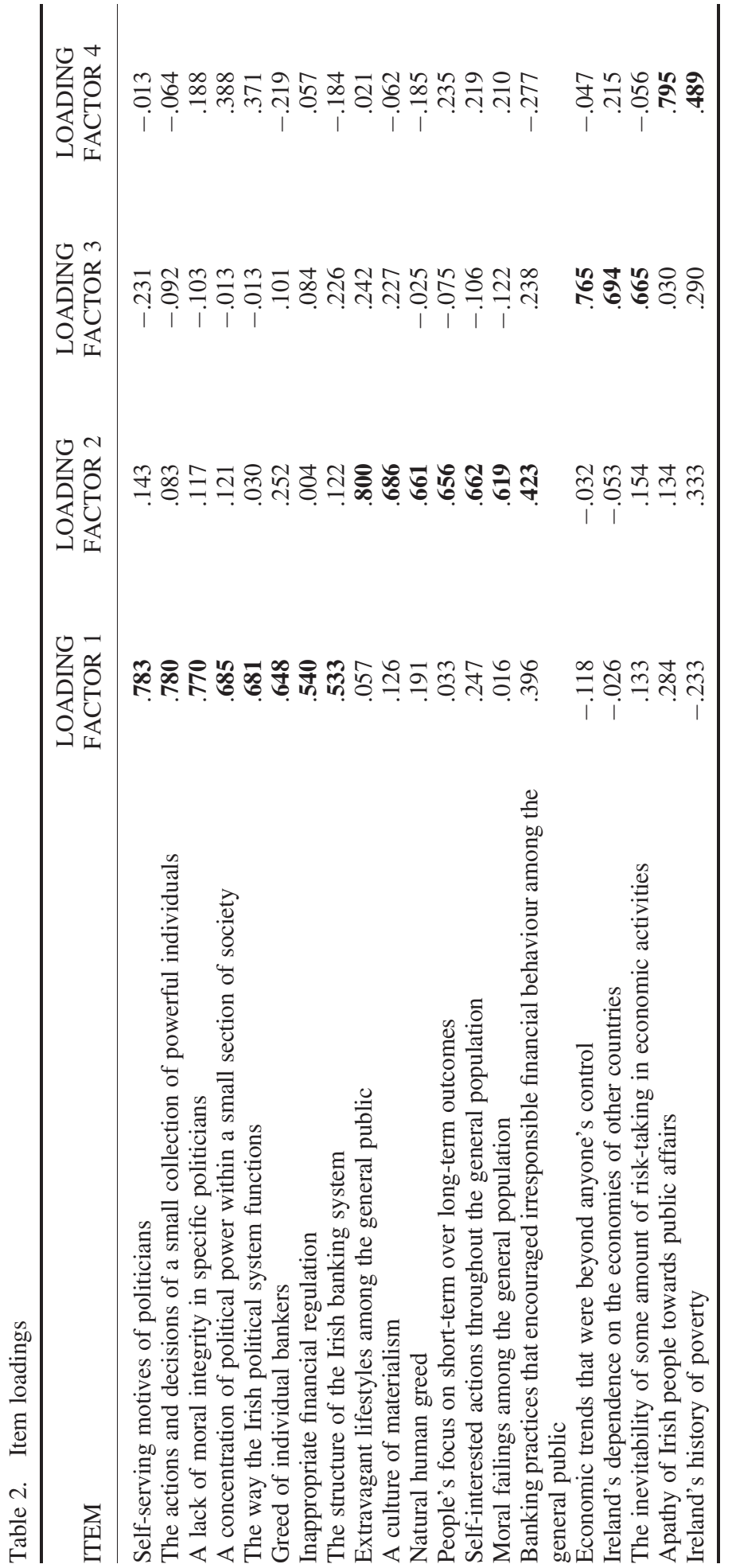


recession. Factor 3 seems to express the idea that the recession was a result of uncontrollable economic factors and that Ireland's recession was economically unavoidable. Factor 4 , finally, suggests that things intrinsic to the Irish nation - its history and the character of its people - were instrumental in the economic crash. These factors have been named Power, Ordinary People, Economic Inevitability and Irish Nation, respectively.

Factor scores. Respondents' factor scores were obtained by calculating the mean of their responses to the items corresponding to each factor. The items corresponding to Power were rated most important in causing the recession $(M=7.65, S D=1.59)$, followed by Ordinary People $(M=6.78, S D=1.49)$, Economic Inevitability $(M=5.55, S D=1.75)$ and finally Irish Nation $(M=4.69, S D=2.02)$. Figure 1 demonstrates these means. A oneway repeated measures ANOVA was conducted to evaluate the difference between these means. Mauchly's test indicated that the assumption of sphericity was violated, $\chi^{2}(5)=21.12, p<.01$. Degrees of freedom were therefore corrected with Huynh-Feldt estimates of sphericity $(\varepsilon=.943)$. Results indicated a significant difference between the factor scores, $F(2.8,387.4)=97.274, p<.001$. Post-hoc $t$-tests with Bonferroni corrections revealed that all four factor scores differed significantly from each other. Statistical analysis demonstrated no effect of sex, age or socio-economic status on factor scores.

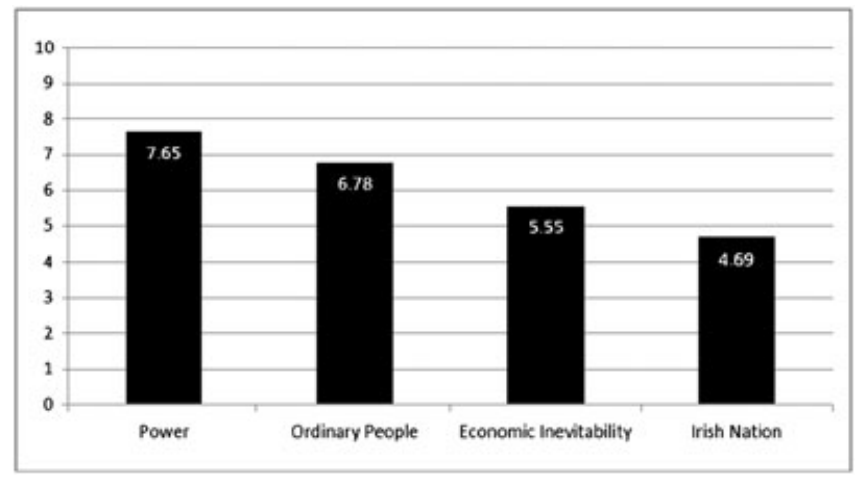

Figure 1. Means of factor scores.

\section{OVERALL RESULTS}

The content of the factors extracted from the survey data corresponds closely with the themes identified in the interview data. Power and Ordinary People materialise as key underlying dimensions in both data sets. The survey factors of Economic Inevitability and Irish Nation, meanwhile, comprise two important threads of the qualitative theme of Fatalism. Naturally, overlap in the results from the two data sources is to be expected as the survey items were derived from the interview data. The triangulation of interest, however, is not of the specific ideas, but of the relationships between them. For example, the areas of banking, politics and power were highly interlinked both quantitatively and qualitatively. This promotes confidence that the themes identified in the thematic analysis represent cohesive explanatory frameworks. Thus, power, ordinary people and fatalism appear to be the key orienting points undergirding lay explanations of the recession. 


\section{DISCUSSION}

This study suggested that three major themes organised lay explanations of Ireland's recession. Most salient was a projection of blame towards the powerful in society. This interacted dynamically with representations of ordinary people's role in the processes leading to the recession: ordinary people were acknowledged to hold some responsibility, though people held back from investing this with full moral culpability. Also observable were representations of the recession in fatalistic terms, giving causal significance to features of the world that transcend any individual, and over which no control is possible.

\section{Power and ordinary people: anchoring, objectification and identity dynamics}

The anchoring, objectification and identity protection functions of social representation were apparent in the themes of Power and Ordinary People. Power emerged as a major anchor for social representations of the recession. Explanations of the crisis were grounded in perceptions of how power operates and in the individuals and groups designated as powerful. In the wake of the recession, quite a clear idea of who was responsible had solidified, objectified in the banker-politician-developer 'triad'. This objectification was emotionally and symbolically loaded and seemed to provide a solid focus for the narrative of the recession as reflecting power's recklessness with the lives of ordinary people.

The direction of blame towards the powerful can be interpreted as an instance of 'othering'. Traditionally research has identified low-status, stigmatised outgroups (such as immigrants, homosexuals or poor people) as the focus for 'othering' (Joffe, 1999). It is interesting that in the present research people located their 'other' by looking up rather than down the social strata. This may partly be an exercise of defensive attribution, motivated by people trying to remove culpability from themselves. This should not however delegitimize this explanatory position; the data shows that people also implicated themselves and other 'ordinary people'. The presence of 'othering' implies identity dynamics that position the powerful as sharply separate from the general population. The elite were represented as disconnected from the public's concerns, resulting in public alienation from the powerful and the systems they represent. The political and economic establishments did not just fail to inspire automatic trust in the public, but elicited active mistrust. Estrangement of the general population from institutional powers was both reflected in and reinforced by the representations of the recession that emerged.

\section{Risk society, reflexivity and fatalism}

A key advantage of SRT is that in exploring representations of one particular issue, it also furnishes an insight into the texture of life in that society more generally. The shift in the direction of 'othering' processes is interesting in this regard, as it is possible that it may indicate social changes ushered in by the risk society. Beck (1992) claims that the risk society encourages a culture of reflexivity, in which ever-present future threat requires routine contemplation of counterfactual scenarios and scrutiny of present circumstances in light of this. This chimes with the work of Giddens (1991), who depicts the late $20^{\text {th }}$ century as a time characterised by the institutionalisation of 'radical doubt' and the end of automatic deference to authority. These changes do not augur well for traditional institutional powers, whose pronouncements and decisions no longer go uncontested. 
Undoubtedly, recent years in Ireland have seen the status of many previously impervious pillars of Irish society (such as the Catholic Church) become tenuous. The current data may reflect an historical context in which people are increasingly ready to 'other' society's powerful strata in orientations towards social problems.

Beck and Giddens are optimistic about the transformative power of reflexivity, portraying it as a means through which people can change social conditions. It is implied that if traditional politics is not sufficiently responsive to the demands of the risk society, the resource of reflexivity enables people to transfer their political engagement to the domain of life politics or sub-politics (Beck, 1999; Giddens, 1991). Beck and Beck-Gernsheim (2001) describe life politics as the forging of links between private actions that have little meaning by themselves and outcomes in which individuals feel themselves agents of global political acts. The present data, however, revealed little evidence of such political efficacy. The sense that people felt helpless and disempowered in their socio-political environment emerged very strongly. Informants recognised, in retrospect, that their actions helped fuel the situation from which the recession developed. They felt, however, that there was nothing they could have done to change the situation in the past, and that there were few ways they could address it in the present. People expressed frustration that power was concentrated in the hands of small, distrusted sectors of society, but lacked the energy or collective efficacy needed to wrest it back. Indeed, they seemed to feel that there was no way in which this could be done, stating that they did not perceive any structures through which ordinary people could meaningfully participate in public life. Respondents did not experience any space - political or sub-political — in which they could satisfactorily act.

This suggests that at the level of actual lived experience, the reflexivity introduced by the risk society may not necessarily be a genuinely empowering resource if opportunity for discursive critique of authority is not matched by opportunity to act on this critique. The old institutional powers were perceived to retain considerable hold over the pathways through which tangible change can be effected. A combination of intense criticism and an inability to channel that into action appeared to result in an atmosphere of bitter resentment mixed with resignation to a disempowered state. The sense of fatalism present in the data links into this feeling of helplessness. In the interviews, people persistently represented themselves as powerless beneath the force of economic currents, international affairs, human nature, national character. Fatalistic responses to public crises could speculatively have far-reaching social effects: implying there is no blame to be apportioned, suggesting nothing can prevent a reoccurrence, justifying the crisis as part of the natural order of things and undermining belief in the power of human agency in structuring our world.

\section{The complexity of lay explanation}

The breadth of representation encompassed in the data is striking. That people did not have an extensive repertoire of economic knowledge at their disposal did not inhibit the construction of complex explanations for the crisis. Instead of recruiting formal economic concepts, people found material for explanation in their social world, drawing upon a wide range of ideas about society, power, morality, public spheres and personhood. The recession was not conceptually 'lifted out' of its social environment to be understood as a distinct, strictly economic event: for most people, the recession was not a strictly economic event. The representations circulating defined the core of the recession as political, social and moral; it was perceived to epitomise 'what was wrong' in Ireland. 
Both explanatory types identified by Leiser et al. (2010) - understandings of the financial crisis focused on the individual and those directed at the systemic level - appeared in the current data. As in that study, moralisation of the crisis by focusing on individuals' moral or cognitive failings was the most salient feature of people's explanatory efforts. Interestingly, however, the clear division between these types that Leiser et al. (2010) found did not materialise in either the qualitative or quantitative portions of this study. Rather, the themes that emerged were holistic ones that combined multiple levels of explanation: Power, for instance, contained references both to personal characteristics of powerful individuals and to an institutional structure that concentrates power in their hands. When power was recruited in understanding the recession, both these dispositional and structural dimensions were simultaneously implicated.

This difference from Leiser et al.'s (2010) results could reflect differences in the research fields. Ireland was particularly sharply affected by the recession, and the economy was paramount in the public agenda at the time of data collection. It is possible that the importance of an issue in a society mediates the level of complexity of the explanations that develop. It is interesting to note that the explanations respondents offered for the recession were not entirely internally coherent: contradictions were evident, both between and within individuals. The projection of responsibility onto the powerful was reined in by acknowledgement that ordinary people also were implicated, which was then qualified by summoning factors mitigating the moral culpability of their actions. This was simultaneously accompanied by representations of the recession as inevitable and uncontrollable, implying that the apportioning of blame is a futile endeavour. Rather than signalling deficiencies or inaccuracies, such states of representational tension may indicate genuine psychological engagement with the issue: people are investing cognitive energy in reflecting on the issue's different dimensions rather than quickly arriving at simple one-dimensional explanations.

\section{Limitations and future directions}

The picture of public thinking provided by the current data corpus is not conclusive or comprehensive. The interviews were limited in number and accessed a restricted range of the population. The survey also was subject to sampling problems, yielding a relatively small sample size in which females, students and younger people were over-represented. This may be particularly important given that students and young people are likely to have limited experience of finance and the labour market relative to the rest of the population. SRT suggests that representations are intimately linked to the groups present in a society: if different groups possess different concerns or projects, this will be reflected in differences in the representations they carry (Bauer \& Gaskell, 1999). The current study did not provide for any systematic comparison between the different groups that segment the wider Irish population. It would be interesting, for example, to investigate how the representations maintained by members of the banker-politician-developer 'triad' may differ from those uncovered in the present data. There are likely to be many aspects of the representations of the recession circulating in Irish society that the present research did not detect. Nevertheless, the clear patterns into which both the quantitative and qualitative data fell give some grounds for confidence that those it did identify are meaningful ones.

It should be clear that this study captured a snapshot of Irish public thinking at one specific historical moment. It does not claim to provide a depiction of representation in Ireland 
that is in any sense permanent or enduring. Social representations are intrinsically embedded in their social context and change as that context does (Jovchelovitch, 2002). The Irish societal context has indeed changed considerably since the time of research: the following months saw further economic decline, recourse to extensive emergency loans from the European Union and International Monetary Fund, and a change of government. Undoubtedly, social representations and public sentiment have evolved alongside such events.

While the particular content of the representations may have changed, however, the data illuminates aspects of the lay explanation process that are likely to persist. The central point is that issues emanating from abstract, expert-dominated domains like economics are made meaningful by grounding them in their social, political and moral context: these dimensions of human experience supply the material on which explanations are built. The anchoring of the recession in ideas of 'power' versus 'ordinary people' gave it a narrative while the objectification of the 'triad' provided a solid focus. It was the process of social representation that facilitated the saturation of the crisis with such meaning, and thus it was social representation that grounded abstract economic processes in issues relevant to people's direct experience of the social world. It is anticipated that in the coming years, risk society-type issues will increasingly dominate the societal agenda. If this is the case, it is important that how people respond to these issues is adequately understood and theorised. SRT appears ideally placed to examine how explanations for such issues are constructed, and it is recommended that future research on responses to public crises adopt SRT as a primary theoretical point of reference.

\section{ACKNOWLEDGEMENTS}

The author would like to thank Dr. Sandra Jovchelovitch and Dr. Helene Joffe for their advice at various stages of this research and two anonymous reviewers for their constructive comments.

\section{REFERENCES}

Bauer, M. W. (2009). The evolution of public understanding of science - discourse and comparative evidence. Science, Technology \& Society, 14, 221-240.

Bauer, M., \& Gaskell, G. (1999). Towards a paradigm for research on social representations. Journal for the Theory of Social Behaviour, 29, 163-186.

Beck, U. (1992). Risk society: Towards a new modernity. London: Sage.

Beck, U. (1999). World Risk Society. Cambridge: Polity Press.

Beck, U., \& Beck-Gernsheim, E. (2001). Individualization. London: Sage.

Bonn, M., Earle, D., Lea, S., \& Webley, P. (1999). South African children's views of wealth, poverty, inequality and unemployment. Journal of Economic Psychology, 20, 593-612.

Braun, V., \& Clarke, V. (2006). Using thematic analysis in psychology. Qualitative Research in Psychology, 3, 77-101.

CSOI (Central Statistics Office Ireland). (2010). Seasonally Adjusted Standardised Unemployment Rates. Retrieved August 5, 2010, from http://www.cso.ie/statistics/sasunemprates.htm

Försterling, F. (2001). Attribution: An introduction to theories, research and applications. Hove: Psychology Press.

Gaskell, G. (2000). Individual and group interviewing. In M. W. Bauer, \& G. Gaskell (Eds.), Qualitative researching with text, image and sound: A practical handbook (pp. 38-56). London: Sage.

Giddens, A. (1991). Modernity and self-identity: Self and society in the late modern age. Cambridge: Polity Press. 
Hewstone, M. (1989). Causal attribution: From cognitive processes to collective beliefs. Oxford: Basil Blackwell.

Howarth, C. (2002). Identity in whose eyes?: The role of representations in identity construction. Journal for the Theory of Social Behaviour, 32, 145-162.

Hume, D. (2007). A treatise of human nature. In D. F. Norton, \& M. J. Norton (Eds.). Oxford: Oxford University Press. (Original work published 1740).

Ichheiser, G. (1949). Misunderstandings in human relations: A study in false social perception. The American Journal of Sociology, 55, 1-70.

Jodelet, D. (1991). Madness and social representations: Living with the mad in one French community. (T. Pownall, Trans.). Los Angeles: University of California Press.

Joffe, H. (1999). Risk and 'the other'. Cambridge: University Press.

Joffe, H. (2003). Risk: From perception to social representation. British Journal of Social Psychology, 42, 55-73.

Joffe, H., \& Haarhoff, G. (2002). Representations of far-flung illnesses: The case of Ebola in Britain. Social Science \& Medicine, 54, 955-969.

Joffe, H., Washer, P., \& Solberg, C. (2011). Public engagement with emerging infectious disease: The case of MRSA in Britain. Psychology \& Health, 21, 1-17.

Jovchelovitch, S. (2002). Re-thinking the diversity of knowledge: Cognitive polyphasia, belief and representation. Psychologie et Société, 5, 121-138.

Jovchelovitch, S. (2007). Knowledge in context: Representations, community and culture. London: Routledge.

Jovchelovitch, S. (2008). The rehabilitation of common sense: Social representations, science and cognitive polyphasia. Journal for the Theory of Social Behaviour, 38, 431-448.

Kelly, M. (2010). Whatever happened to Ireland? Centre for Economic Policy Research Discussion Paper No. DP7811. Retrieved August 5, 2010, from http://papers.ssrn.com/sol3/papers.cfm? abstract_id=1611507

Leiser, D., \& Drori, S. (2005). Naive understanding of inflation. Journal of Socio-Economics, 34, 179-198.

Leiser, D., Bourgeois-Gironde, S., \& Benita, R. (2010). Human foibles or systemic failure - Lay perceptions of the 2008-2009 financial crisis. Journal of Socio-Economics, 39, 132-141.

Moscovici, S. (1988). Notes towards a description of Social Representations. European Journal of Social Psychology, 18, 211-250.

Moscovici, S. (2008). Psychoanalysis: Its image and its public. (D. Macey, Trans.). Cambridge: Polity Press. (Original work published 1961).

Office for National Statistics. (2005). The National Statistics Socio-Economic Classification User Manual. Retrieved July 28, 2010, from http://www.statistics.gov.uk/methods_quality/ns_sec/ downloads/NS-SEC_User_2005.pdf

Roland-Lévy, C., Pappalardo Boumelki, F.-E., \& Guillet, E. (2010). Representation of the financial crisis: Effect on social representations of savings and credit. Journal of Socio-Economics, 39, 142-149.

Sévon, G., \& Weckström, S. (1989). The development of reasoning about economic events: A study of Finnish children. Journal of Economic Psychology, 10, 495-514.

Wagner, W., \& Kronberger, N. (2001). Killer tomatoes! Collective symbolic coping with biotechnology. In K. Deaux, \& G. Philogene (Eds.), Representations of the social - bridging theoretical traditions (pp. 147-164). Oxford: Blackwell. 